\title{
A Study to Trial the Use of Inertial Non-Optical Motion Capture for Ergonomic Analysis of Manufacturing Work
}

\author{
Sarah R Fletcher*, Teegan L Johnson, John Thrower \\ Centre for Advanced Systems, Cranfield University, Cranfield, Bedfordshire, MK43 OAL, UK \\ *s.fletcher@cranfield.ac.uk
}

\begin{abstract}
It is going to be increasingly important for manufacturing system designers to incorporate human activity data and ergonomic analysis with other performance data in digital design modelling and system monitoring. However, traditional methods of capturing human activity data are not sufficiently accurate to meet the needs of digitised data analysis; qualitative data is subject to bias and imprecision and optically derived data is hindered by occlusions caused by structures or other people in a working environment. Therefore, to meet contemporary needs for more accurate and objective data, inertial non-optical methods of measurement appear to offer a solution. This paper describes a case study conducted within the aerospace manufacturing industry, where data on the human activities involved in aircraft wing systems installations was first collected via traditional ethnographic methods and found to have limited accuracy and
\end{abstract}


suitability for digital modelling, but similar human activity data subsequently collected using an automatic non-optical motion capture system in a more controlled environment showed better suitability. Results demonstrate the potential benefits of applying the inertial non-optical method in future digital modelling and performance monitoring but also the value of continuing to include qualitative analysis for richer interpretation of important explanatory factors.

Keywords: Motion Capture, Human Data Analysis, Manufacturing System Design, Digital Human Modelling

\section{Introduction: the need for accurate human activity analysis}

It seems obvious that if we want to effectively design and monitor the performance of any working system we need to have a good understanding of all components of that system. As we currently face the 'Industrie 4.0' revolution of digitised and data driven 'cloud' manufacturing, system reliability will depend on informatics using valid data from all system components including human factors [1]. Traditional approaches for the design and analysis of manufacturing systems information have not attended to human data with the same level of interest and analysis as that of mechanistic elements despite that we know it can cause considerable impacts on overall system performance [2]. However, with increasing levels of automation in manufacturing changing the nature of human work it is clear that people will remain vital for providing the dexterity and 
flexibility needed for assembly and product customisation $[3 ; 4 ; 5]$, and are increasingly being upskilled as supervisors / maintainers of technology and automation [6].

Therefore, all of the various system design approaches still "all depend on two common things: acquiring technology and the effective operation of this technology by humans"

[8]. It is crucial that we are equipped to supply accurate human data and ergonomic analysis to ensure effective design of future systems and intelligent automation.

Industrial techniques for capturing and analysing human activity have long been focused on minimising and 'designing out' variability and, as such, are designed to standardise the data they produce rather than account for true representations of activity. Work study derived 'predetermined motion time systems' such as methods-timemeasurement (MTM) [9], are still widely used to identify individual elements of an activity and apply standard motion times based on a limited number of (or even singular) observations of manual task performance [10]. This technique is therefore useful for identifying salient common task steps in order to create work standards / standard operating instructions, but is inevitably vulnerable to limitations as it depends on the observer's view and appreciation of the situation and environment, the observer's existing knowledge and capability and, of course, the observed worker's reliability in reflecting typical performance. Industrial designers have increasingly been advocating the integration of human data and ergonomics analyses in computer aided design (CAD) 
simulations [11]. However, the fidelity of simulations has been restricted by software functionality and suitability / validity of anthropometric data [12].

Ergonomic techniques for analysing industrial human activity have traditionally focused more on capturing human variability via ethnographic and psychophysical data collection methods on the shop floor although these are also vulnerable to the inherent problems of observation and subjectivity. Systematic observations can provide reliable data but accuracy is dependent on the capabilities of ergonomists to estimate key factors such as motion and force [13] and on the reliability of workers' self-reports and selfdirected work performance [14]. We have also long known that observations are vulnerable to demand characteristics or observer effects whereby an individual's awareness of being observed can influence their behaviour such that they perform according to what they perceive is required or desirable [15]. This effect can reduce over time and repetition but it is obviously more difficult to minimise with a limited number of observations.

Video recording is a less intrusive method of observational data capture which can be comparably accurate to direct measurement, but it is time-consuming to analyse, requires careful positioning of cameras, and is easily impaired by occluded views and viewing angle parallax from the multiple cameras needed for 3D visibility [16]. In the 
shop floor environment video monitoring may also evoke workforce resistance as it may connote wider performance monitoring.

Optical motion capture is also a camera based technique but instead gathers image sensor / tracking derived data rather than obtaining real footage to identify the moving object's 3D positioning, thus eliminating the need for painstaking video analysis. This might also be a more palatable measure for the workforce as it does not observe anything other than physical positioning. A number of systems are commercially available from small single sensor devices (e.g. Kinect) to larger scale multiple-camera systems (e.g. Vicon). However, because optical systems rely on camera / sensor visibility they are also vulnerable to obstructions in dynamic / operational environments [17]. Moreover, as the accuracy offered by multi-camera systems hinges on triangulation of tracked data in 3D space, very precise and unoccluded camera positioning is needed, which may be a challenge to set up in busy operational shop floor environments.

Clearly, no camera / visibility based method will be suitable for data collection within manufacturing systems where operators need to perform tasks from inside structures or where there are potential moving obstacles to the field of view. These problems demonstrate the need for accurate and ideally automatic human data capture which will be suitable for dynamic and occluded / partially occluded environments but minimise 
observational intrusion. A solution is now being offered by developments in non-optical motion capture technology.

Non-optical systems offer automatic human motion data capture without the need for a visual field, therefore enabling automatic data capture from areas where visibility is impaired or impossible. Originally pioneered by cinematic applications, inertial nonoptical motion capture systems are becoming more widely marketed (e.g. Xsens, Animazoo/Synertial) as their combined inertial measurement units (IMUs) of gyroscope, magnetometer, and accelerometer, typically worn via a body suit, offer relatively good accuracy but without the need for visibility. This eliminates the need for external cameras and all of the associated problems of setting up and obstruction that entails in the shop floor environment, and offers a more discreet and unobtrusive measure for shop floor workers. Additionally, inertial non-optical motion capture technology enables direct data streaming into CAD programmes for retrospective or real time analysis which means it not only serves the design needs but also potentially for real time system monitoring in future digitised systems.

This paper describes a case study in which human manufacturing task activity was captured for ergonomic assessment in two component studies: first, using traditional methods in a real operational system which proved limited and unsuitable for accurate digital human modelling and, second, in an experimental study using inertial non- 
optical motion capture technology in a mock-up facility which showed enhanced capabilities for automatic data collection without the need for visibility. In the following section we first describe the context of the case study as this explains the relevance of the type of manufacturing and human work tasks that were examined in this study.

\section{The case study context: aircraft wing production}

The case study described in this paper involved collecting human activity data in the performance of manufacturing tasks in aircraft wing manufacture. This context is relevant because the aerospace manufacturing industry still relies heavily on human operators for assembly work, often in occluded structures, and due to consumer demand and economic importance it will inevitably be at the forefront of manufacturing system digitisation and so will be looking for effective data capture.

The production of aircraft wings is a good example of where a large amount of human work is required from beginning to end of the manufacture. Early on in the process the wing box structure itself is built into a sealed unit that is divided up into a series of cavities by an internal skeleton frame structure of ribs and spars. After this there are various sub-assemblies and 'systems installations' to be performed which involve the manual fitting of a vast number of components inside internal cavities (e.g. for fuel, hydraulics, electrics, electronics systems). This work requires human operators to physically reach in or fully climb into the internal spaces, often having to adopt 
awkward and uncomfortable physical positions for considerable periods of time.

Therefore, information on the physical activities necessary for this demanding type of work should certainly be included in manufacturing design and monitoring activities and in the design of future intelligent automation which may be employed to work in collaboration with the operators. The aim of the field study was to study the human activity involved in these systems installations tasks using traditional and innovative methods and evaluate the methods.

\section{Method}

This case study comprised of two developmental data collection phases and approaches. First, a field study in a fully operational aircraft wing production facility was conducted to study installation tasks being performed using traditional, ethnographic data collection methods to produce qualitative data. Second, an experimental study was then conducted in a controlled test facility where non-optical motion capture system was trialled using participants performing representative assembly tasks in a mock-up of the aircraft wing to produce quantitative data. The two studies are developmental and contextually related, but as the designs are completely different their data are not linked. They are intended to, together, illustrate the value and limitations of traditional observation based human analysis methods and trial a new innovative and technology based approach. 


\section{Field study: method}

The aim of the field study was to obtain data from real operators working on systems installations tasks in the live working environment using traditional ethnographic methods and evaluate the utility of this approach and data for ergonomic analysis.

The field study was conducted at a fully operational aircraft wing manufacturing facility in the UK, specifically in the downstream systems installations area of production which has a workforce of approximately 350 people, all specifically skilled in the assembly and fitting of a vast number of individual components. Due to the large number of different systems being installed in this area it was necessary to down select a limited number of processes for the study, so only three processes were chosen on the basis that they all involved a high degree of human effort but even these amounted to several hours of human work activity. To study these three processes 9 operators were recruited by purposive sampling as ideal participants for the study (by their shift managers) on the basis of their familiarity with the selected systems installation processes and their availability during the data collection period on site.

A number of limitations emerged as the ethnographic approach was conducted in this particular work environment. First, it is customary for an analysis of tasks to begin with a review of relevant Standard Operating Instructions (SOIs) to gather an indicative benchmark for performance and procedure. However, at the time of data collection SOIs 
were not available so preliminary off-line interviews were held with participants to begin examining the nature of the processes and work sequences. Then, on-line observations and 'talk-through' interviews were conducted so that participants could also try to physically demonstrate their task activities. Second, due to commercial sensitivities it was not permissible to use photography to capture images for ergonomic assessment and the occluded environment coupled with obstructions caused by equipment and other people meant visibility was severely impaired. Third, it was soon apparent that there was too much variability in the system to rely on designated timings and as the work is also so craft based, relying greatly on tacit skills and experience, there were also variations in personal task performance methods. Thus, with limited visibility and standard specifications of the tasks, and to avoid disrupting productivity, the data collection was restricted to the subjective reports and observations made with the small number of participants, making the analysis interpretive. This ethnographic approach provided rich in-depth qualitative data from real operators which indicated key ergonomic issues. The data was then iteratively reviewed and revised with the participants to achieve a basic deconstruction of tasks and develop an overview of generalised task steps (physical and cognitive) needed to achieve specified goals.

The qualitative data from observations and interviews was collated and interpreted, and the set of generalised task steps was then used as a source of information for the construction of computer aided design (CAD) models (using Delmia Human; Dassault 
Systemes). This activity was intended for ergonomic analysis and representation of the ergonomic difficulties found, however the qualitative and variable nature of the data made it unsuitable for digital modelling. The data was also scrutinised using thematic analysis so that common themes could be identified.

\section{Experimental study: method}

Due to limitations found in the collection and application of qualitative data from the live working environment of the field study the aim of the experimental study was to derive more objective data regarding the ergonomic difficulties associated with the performance of systems installation tasks in a controlled environment study.

The experimental study was conducted at a testing facility belonging to the organisation who hosted the field study but in a different UK location. The controlled environment was chosen to achieve more reliable data and reduce the risk of confounding factors or causing further disruptions to productivity in a live operational environment.

A life size model wing box replicating a central section of the specific aircraft wing that had been involved in the field study was mounted onto a jig and held at a horizontal position for the data collection for this study, thus reflecting the shop floor orientation. Out of a number of possibilities, a set of four replica tasks were selected, designed and positioned at different areas of the wing box model to reflect the characteristics and the 
positioning of real systems installations tasks to address the factors found in the earlier field study to be of underlying importance to ergonomic issues. This meant the tasks would require the same physical reach and body posture as the shop floor work and thus reflect the same ergonomic difficulties that had been identified in the field study. The four replica installation tasks and the ergonomic difficulties they represented were:

Task 1 - participants were required to install screws through a retainer and fit nuts on the other side of a rib to secure a pipe; this represented difficulties of fitting components at either side of a rib.

Task 2 - participants were required to insert a pipe into upper and lower housings on adjacent ribs; this reflected difficulties when a degree of manual force is needed within the structure.

Task 3 - participants were required to insert and tighten a screw to secure a bracket to the rib; this represented difficulties of reaching tasks positioned furthest away from access holes.

Task 4 - participants were required to fit a component by securing it with screws to brackets on the side rib in a centrally positioned area; this reflected an alternative task but also at a location at reach from the nearest access hole. 
The wing box model and replica tasks provided a likeness of the real operational conditions as it incorporated true dimensions of the wing's internal spaces and comparable systems installation tasks (although of short duration which did not reflect longer process times of the real system). Figure 1 illustrates the positions of the four replica tasks in the wing section model.

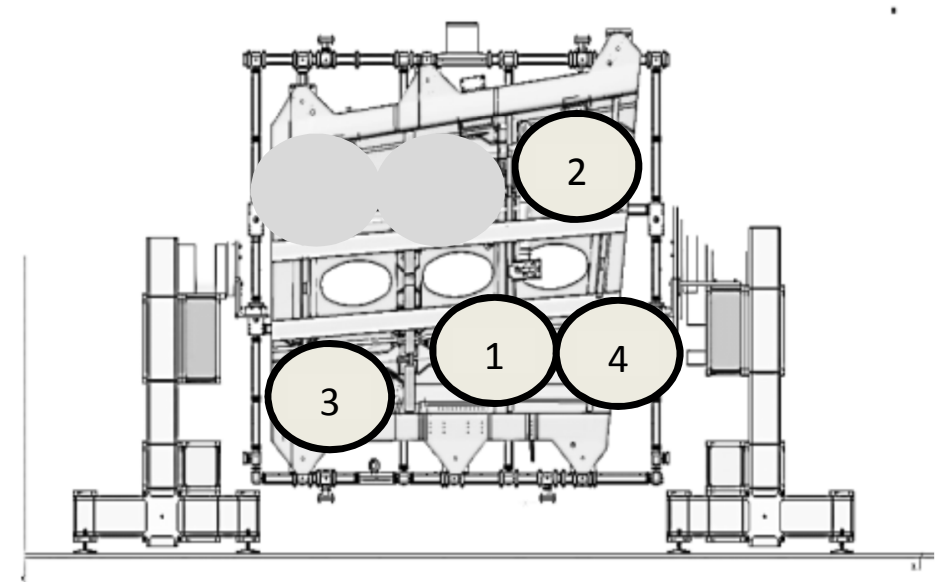

Figure 1 Position of replica tasks in the wing section model

Non-optical motion capture technology was selected as the method for collecting objective data without visibility. A whole-body suit which automatically records key body segment and joint movements via 17 inertial measurement units (IMUs) comprising gyroscope, accelerometer and magnetometer sensors was used to instantly provide visual output and metric data even when the participant is obscured from view (IGS-Bio v1.8; Animazoo Ltd.). 
Participants $(\mathrm{n}=10)$ were volunteers from the same manufacturing organisation's local workforce, who held knowledge of wing design and manufacture to varying degrees but were not experienced operators. It was not possible to use the same operators that had participated in the field study due to the distance between locations, but this was not considered a confounding factor as their skill and experience levels were not required. This study was designed to capture the physical postures people need to adopt in order to perform (or enact) the representative installation tasks and it did not evaluate task performance - therefore the impact of skill would be minimal and it was of greater importance to ensure the sample represented a good range of physical statures.

The procedure involved the participants wearing the non-optical motion capture suit and then performing each of the representative systems installations tasks within the mockup wing box, in turn, with complete freedom to approach and try out the task as they judged best. This independence reflected the idiosyncrasy and variability between operators in how they approached tasks that had been observed in the real work environment and any skill variances within this set of participants. The sequence in which tasks and orientations were presented to participants was randomised to counter any potential order effects.

As the purpose of this study was to generate and analyse more objective data regarding the ergonomic difficulties associated with the performance of systems installation tasks 
it was determined that extremes of posture would be the focus for analysis rather than the dynamic activity. The option to undertake digital ergonomic analysis was rejected due to the current limitations of digital modelling: several ergonomic issues observed in this study, and in the field study, involved lower limb strain due to the need to crouch and keep knees bent for periods of time but available CAD software can only deal with upper body analysis. Therefore, in order to trial the non-optical data capture system more comprehensively and include key ergonomic issues that had been identified in the first field study, it was necessary to analyse the whole body. The 'Rapid Entire Body Assessment' (REBA) technique was selected as this is a widely used method involving systematic calculation of overall musculoskeletal risk based on scores of each body part positioning [18].

REBA analysis is performed on single postures that are selected based on one or all of the following criteria:

- They are the most difficult postures / tasks (based on subjective report and observation)

- They are postures sustained for the longest periods of time

- They are postures where the highest force loads occur

Therefore, the first part of this analysis involved reviewing the visual output of the motion capture in which a manikin displays the human participant's postures and 
movements and identifying extremes of posture within single key visual output frames. Using these key frames the most extreme postures can then be evaluated systematically using the traditional REBA hand score method for each key frame.

\section{Results}

The two phases of this work produced very different forms of data and therefore there is no direct linkage and the results for each of the two component studies are provided separately. Additionally, as the raw data pertains to assessments of specific processes that are commercially sensitive these cannot be reported. Therefore, the results presented below have had to be sanitised such that any detailed / identifying information has been removed and only overall results are reported.

\section{Field study: results}

As the field study set out to obtain data directly from systems installations operators but it was not possible to obtain clear visibility or photographic capture of the work being performed it was not possible to conduct formal ergonomic assessments based on observations or captured images and, as described, thematic analysis was applied to the qualitative data to identify common issues. The results presented in Table 1 are, therefore, a summary of the most commonly observed and reported ergonomic and task difficulties that pertain to all of the three systems installation processes being examined. 


\section{Table 1: Key ergonomic issues emerging from the field study's data analysis}

\begin{tabular}{|c|c|c|}
\hline & Observed / Reported Issue & Explanatory / Analytical Notes \\
\hline 1 & $\begin{array}{l}\text { Discomfort and physical strain from } \\
\text { having to stretch, twist and adopt } \\
\text { awkward postures to reach inside the } \\
\text { structure using partial body entry. }\end{array}$ & $\begin{array}{l}\text { Partial body entry involves entering the head / shoulders } \\
\text { /arms / hands - the extent of body part entry depends on } \\
\text { the area of the wing and related size of access hole. } \\
\text { Reaching tasks may require physical contortions e.g. } \\
\text { twisting from the waist, and working with arms } \\
\text { overhead and behind the centre of the spine. }\end{array}$ \\
\hline 2 & $\begin{array}{l}\text { Discomfort and physical strain caused } \\
\text { by full body entry and positions } \\
\text { required to perform in-tank tasks. }\end{array}$ & $\begin{array}{l}\text { Full body entry requires a degree of physical effort } \\
\text { simply for entry and egress, but also for some tasks it } \\
\text { requires having to stay within cramped, dark, hot and } \\
\text { noisy conditions for prolonged periods. Some full entry } \\
\text { tasks also involve laying across ribs which, even with } \\
\text { protective mats, can cause pressure on the body parts. }\end{array}$ \\
\hline 3 & $\begin{array}{l}\text { Difficulties working inside the wing } \\
\text { box from the pallet trolley where its } \\
\text { support posts are obstructive; causes } \\
\text { frequent leg swapping to alleviate the } \\
\text { pressure on load-bearing legs when in } \\
\text { stooped positions. }\end{array}$ & $\begin{array}{l}\text { The pallet on which the wing sits can be an obstacle in } \\
\text { itself when operators have to work using access holes } \\
\text { that are near to supporting posts. When tasks in this } \\
\text { central region require partial upper body entry taller } \\
\text { operators need to adjust to the height by stooping and } \\
\text { this causes the need to swap legs. }\end{array}$ \\
\hline 4 & $\begin{array}{l}\text { Upper body and arm strain from } \\
\text { working overhead with arms above } \\
\text { shoulder from under the wing. }\end{array}$ & $\begin{array}{l}\text { Having to work up inside the wing with arms stretched } \\
\text { overhead causes shoulder and upper limb strain even } \\
\text { when working from chairs. }\end{array}$ \\
\hline 5 & $\begin{array}{l}\text { Difficulty and discomfort executing } \\
\text { tasks blindly when unable to see or } \\
\text { from using mirrors to see. }\end{array}$ & $\begin{array}{l}\text { Due to the complexity of systems and the restricted } \\
\text { internal space operators sometimes cannot see the area / } \\
\text { task at which they are working. Sometimes mirrors help } \\
\text { but often they work blindly, feeling their way around to } \\
\text { complete the task which can cause physical strains. }\end{array}$ \\
\hline 6 & $\begin{array}{l}\text { Difficulty and discomfort executing } \\
\text { tasks too close to face when head is } \\
\text { entered into the tank to view / reach. }\end{array}$ & $\begin{array}{l}\text { Further towards the tip of the wing where access holes } \\
\text { are smaller it may be necessary to only enter the head } \\
\text { and hands / arms via the access hole. In certain areas this } \\
\text { means that space is so restricted the operator needs to } \\
\text { complete a task very near to the face which is awkward. }\end{array}$ \\
\hline 7 & $\begin{array}{l}\text { Difficulties installing conduits / cables } \\
\text { due to semi-rigidity and need for two } \\
\text { operators }\end{array}$ & $\begin{array}{l}\text { Conduits and cabling are essentially larger and more } \\
\text { flexible components which can be difficult to } \\
\text { manoeuvre and install without assistance. }\end{array}$ \\
\hline 8 & $\begin{array}{l}\text { Task difficulty if cable ties not } \\
\text { tightened to suitable tautness. }\end{array}$ & $\begin{array}{l}\text { Cable ties are used widely within the structure to } \\
\text { maintain components but if not installed to correct } \\
\text { tension at an earlier installation this can hinder } \\
\text { subsequent installations. }\end{array}$ \\
\hline 9 & $\begin{array}{l}\text { Difficulties when components are } \\
\text { installed out of sequence; requires } \\
\text { removal and replacement and skin } \\
\text { damage to hands / arms due to reduced } \\
\text { space / access. }\end{array}$ & $\begin{array}{l}\text { Process related variabilities may cause installations to be } \\
\text { performed out of sequence. When one component fitting } \\
\text { is delayed other components may continue to be fitted } \\
\text { causing an obstruction. This means either the available } \\
\text { space is now limited and causes discomfort or there is a } \\
\text { need for disassembly and reassembly. }\end{array}$ \\
\hline
\end{tabular}




\begin{tabular}{|c|c|c|}
\hline 10 & $\begin{array}{l}\text { Task difficulty of anti-clockwise } \\
\text { positioning / tightening on right hand } \\
\text { wings. }\end{array}$ & $\begin{array}{l}\text { Right hand (starboard) wings are designed such that } \\
\text { some screw / bolt tightening requires anti-clockwise } \\
\text { tightening which is unconventional and operators find } \\
\text { this more difficult than a conventional clockwise torque. }\end{array}$ \\
\hline 11 & $\begin{array}{l}\text { Task difficulties caused by need to } \\
\text { prepare components before fitting. }\end{array}$ & $\begin{array}{l}\text { Some assembly needs to be made prior to installation } \\
\text { into the wing and this presents a task / time performance } \\
\text { difficulty due to the design. }\end{array}$ \\
\hline 12 & $\begin{array}{l}\text { Communications difficult when tasks } \\
\text { require collaboration at distance. }\end{array}$ & $\begin{array}{l}\text { Some tasks require operators to work together but at a } \\
\text { distance, such as when one operator needs to test an } \\
\text { installation but another operator is situated further away } \\
\text { to monitor the test equipment. Due to distance and the } \\
\text { noisy environment the communication may be difficult. }\end{array}$ \\
\hline 13 & $\begin{array}{l}\text { Skin damage / inefficiencies due to } \\
\text { cleaning materials spillage (e.g. } \\
\text { sealant). }\end{array}$ & $\begin{array}{l}\text { Some systems installation activities require the } \\
\text { application and excess-removal of chemical materials } \\
\text { which may cause irritation to exposed skin. }\end{array}$ \\
\hline 15 & $\begin{array}{l}\text { Difficulties when operator needs to } \\
\text { work on both sides of a rib to fit } \\
\text { components. }\end{array}$ & $\begin{array}{l}\text { Many installations involve working at both sides of a } \\
\text { rib, e.g. to hold a component one side but apply fixing } \\
\text { components on the other. This can be very difficult } \\
\text { requiring another operator to assist or sometimes the use } \\
\text { of auxiliary materials to hold things in place. }\end{array}$ \\
\hline 16 & $\begin{array}{l}\text { Strains caused by manual handling: } \\
\text { components and tools / equipment / } \\
\text { trolleys }\end{array}$ & $\begin{array}{l}\text { The movement of large components, equipment and } \\
\text { trolleys holding smaller pieces can be heavy and } \\
\text { cumbersome, causing physical strain. }\end{array}$ \\
\hline 17 & $\begin{array}{l}\text { Difficulties in applying force and use } \\
\text { of tools in restricted spaces }\end{array}$ & $\begin{array}{l}\text { Due to the confined space inside the wing operators } \\
\text { sometimes find it difficult to use equipment and / or } \\
\text { apply force because they are physically restricted. }\end{array}$ \\
\hline
\end{tabular}

As Table 1 illustrates, the most common ergonomic issues are predominantly relevant to this specific type of work and the internal confines / design of the wing. This confirms the relevance of this area of work, as there is clearly a need to establish accurate data to understand the problems and develop remedial interventions to improve the working conditions.

Although not evident in the above table, clear individual differences between the way in which operators performed the same tasks were observed. These might be due to a 
number of reasons such as training, experience, physical stature and reach abilities, personal preferences and ideas or innovations for improving task performance. The qualitative data also revealed that operators described idiosyncratic methods or ways of coping with difficulties.

Using the generalised task steps that had been produced with the participants, an attempt was made to create CAD simulations which would demonstrate these ergonomic issues. However, this activity was problematic because although the task steps could be followed the physical positions had to be based on estimations rather than objective / metric data. Overall, it was found that the models created in this way made the tasks and physical positions appear much easier and less demanding than had actually been observed during data collection (see Figure 2) and without more detailed information the ergonomic analysis functions in the software were of little use.

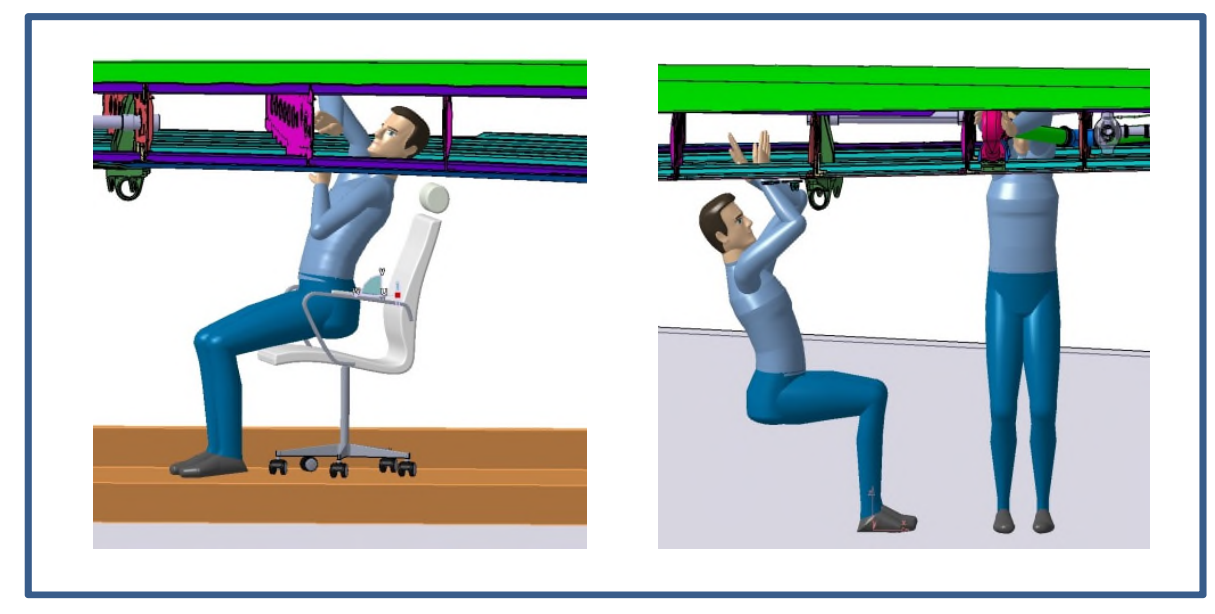

Figure 2. Examples of CAD models not reflecting true difficulty 
Despite its limitations, the field study data and CAD modelling revealed that the various ergonomic difficulties associated with systems installations tasks could generally be attributed to one of two types: task location (position within the wing box) and task characteristics (physical attributes of the task). These factors thus informed the design of the subsequent experimental study, as the participant tasks were designed to addresses both of these issues.

\section{Experimental study: results}

The non-optical motion capture system recorded all physical movements made by each of the ten participants as they performed the four replica tasks inside the wing box. However, only three of the tasks were found reachable by all participants in this study Task 3, the task positioned furthest away from access holes, was declined by most of the participants who considered it was impossible. Therefore, although the output data was vast as it included every small and incremental motion the analysis was reduced to only extreme static postures pertaining to three tasks.

The REBA analysis involves three principal stages of scoring and results tables:

Table $\mathrm{A}=$ neck, trunk and leg position scoring with additional weighting scores for load / force (weights incurred by using components / equipment) 
Table B = upper arms, lower arms, and wrist scoring with additional weighting for 'coupling' (the handling of components / equipment) if necessary.

Table $\mathrm{C}=$ scores from steps 1 and 2 added together with final weighting adjustment if necessary for 'activity' (posture duration, rapidness of change, motion repetitiveness).

Thus, the final scores in Table $\mathrm{C}$ denote the overall scores assigned to a given posture, across the body parts and weightings. This is then used to evaluate musculoskeletal risk levels and remedial action urgency as shown in the Risk /Action matrix in Table 2.

\section{Table 2 REBA Risk / Action Levels}

\begin{tabular}{|c|c|l|l|}
\hline Action level & REBA score & \multicolumn{1}{|c|}{ Risk Level } & \multicolumn{1}{c|}{ Action } \\
\hline 0 & 1 & Negligible Risk & None Necessary \\
\hline 1 & $2-3$ & Low Risk & Maybe Necessary \\
\hline 2 & $4-7$ & Medium Risk & Necessary \\
\hline 3 & $8-10$ & High Risk & Necessary Soon \\
\hline 4 & $11+$ & Very High Risk & Necessary Now \\
\hline
\end{tabular}

As this experimental study set out to capture static extreme postures and not dynamic activity the replica tasks were designed to elicit realistic physical reaching and positioning but not reproduce coupling or load weights. This means that each participant's Table C scores pertain only to the total scores made for their neck, trunk, 
leg, upper arm, lower arm and wrist positioning during the most extreme postures they adopted per task, such that there were three final Table $\mathrm{C}$ scores per participant.

To establish an overall score for each of the three tasks, which would indicate its general risk level, the mean average of all ten participants' Table C scores was calculated per task. Using the REBA Risk /Action matrix illustrated in Table 2 these scores indicated the levels of musculoskeletal risk and remedial action required for each of the tasks. These overall results are shown below in as shown in Table 3.

Table 3. Total REBA Scores (and Standard Deviations), Risk and Action Levels

\begin{tabular}{|l|c|c|c|}
\hline & Task 1 & Task 2 & Task 3 \\
\hline Final averaged Table C scores & $6.88(2.30)$ & $8.30(2.41)$ & $6.67(1.97)$ \\
\hline REBA risk level & Medium Risk & High Risk & Medium Risk \\
\hline REBA action level & 3: Necessary & 4: Necessary soon & 3: Necessary \\
\hline
\end{tabular}

As this analysis does not include additional weighting factors usually included in the REBA method the results presented above inevitably reflect lower scores than would be found in scoring for real systems installations work where weighting values would of course be added for loads, couplings, duration and dynamics of activities. Thus, despite the limitations of this study and its representation of real shop floor activity, the motion capture data already shows us that ergonomic conditions in the current system warrant action to reduce musculoskeletal risk, as two tasks were evaluated to be of medium risk 
and in need of action and the other involved high risk that is in need of more rapid attention. The ability to gather motion capture data suitable for postural analysis from within an occluded environment was demonstrated.

\section{Conclusions and Recommendations}

Although the two component studies of this research could not be directly linked, together they demonstrate the potential value in engaging both operator participation and innovative technologies such as inertial non-optical motion capture to obtain more accurate and reliable real world data. Overall, this work demonstrates the values of both subjective and objective which will now be discussed.

The field study component applied iterative ethnographic methods which provided rich data using the valuable participation of experienced operators as subject matter experts to break tasks down into individual process steps. This revealed differences in how operators approached their tasks which would not have been achieved using just observation or physical motion capture. Due to the limited participant sample and range of processes examined it was not possible to ascertain commonalities or best practices for tasks so further work would benefit from a wider audit covering a wider range of tasks especially for remedial design work or for the development of intelligent automation to supplement / assist the human work. However, future system design activities should not neglect to incorporate direct qualitative input from operators as 
subject matter experts as this contains important explanations for working practices and innovations that would be missed by a purely objective approach.

The qualitative data captured during the field study was not suitable for one-to-one transfer into CAD models which made human activities look much less difficult than they were actually known to be. The differences between operators' approaches coupled with operational variabilities meant estimations and assumptions had to be made about the standard sequence of steps and timings. Clearly, despite the richness and depth of qualitative data, it is not suitable for recreating scenarios accurately unless combined with some metric data.

Metric data derived from non-optical motion capture will be ideal for enabling statistical analysis of performance and automatic data feed into CAD for design, and the visual output was invaluable for reviewing physical activity and extreme postures. Moreover, it enables collection of data from within occluded environments and structures which has not before been possible. However, there is still a need to test the accuracy of these systems and the utility of only using digital modelling in manufacturing design [19]. As this study demonstrated, the lack of capability in current CAD softwares for conducting lower limb ergonomic analysis can be a major limitation. A wider set of CAD ergonomic analysis functions are needed so that integration with motion capture can be better exploited for full body analysis. 
Non-optical motion capture, CAD and other objective design tools can be effective in identifying a range of static physical postures [20] but these methods do not incorporate more dynamic or cognitive aspects of a task. This means current technologies for human analysis are adequate for physical ergonomic appraisal but insufficient as a comprehensive design methodology as we would benefit greatly from understanding not only just how people are likely to behave but also why.

The experimental study revealed that several participants expressed that they were unable to perform one of the tasks. As the tasks were designed to represent those of real systems installations work and do require reaching such extreme positions in the wing box this reflects that experienced operators develop the specific skills needed to reach difficult areas so this underlines the need to use real operators as future participants and using non-optical motion capture in the real operational system would achieve higher fidelity that can be achieved in the experimental condition.

Limitations of the field study data collection were largely due to commercial sensitivities and efforts not to disrupt production but also there were some concerns regarding the collection of individuals' performance-related data. Although worker performance capture has historically been a sensitive issue it is going to have to be addressed and surmounted in the near future as we approach mass digitisation of 
manufacturing systems and a much increased level of data collection and monitoring. Motion capture offers a less intrusive method for human work analysis.

\section{Acknowledgements}

The authors wish to thank all anonymous participants who assisted in this study for their time and patience, and to the various engineers and managers who also enabled the collection of data. This research received no specific grant from any funding agency in the public, commercial, or not-for-profit sectors.

\section{References}

[1] Xu, X. (2012). From cloud computing to cloud manufacturing. Robotics and Computer-Integrated Manufacturing, 28(1), 75-86.

[2] Fletcher, S.R., Baines, T.S., \& Harrison, D.K. (2008). An investigation of production workers' performance variations and the potential impact of attitudes. International Journal of Advanced Manufacturing Technology, 35, 1113-1123

[3] Ding, Z. \& Hon, B. (2013). Constraints analysis and evaluation of manual assembly. CIRP Annals-Manufacturing Technology, 62(1), 1-4.

[4] Hu, S. J., Ko, J., Weyand, L., ElMaraghy, H. A., Lien, T. K., Koren, Y., Bley, H., Chryssolouris, G., Nasr, N., \& Shpitalni, M. (2011). Assembly system design and 
operations for product variety. CIRP Annals-Manufacturing Technology, 60(2), 715733.

[5] Ma, L., Zhang, W., Fu, H., Guo, Y., Chablat, D., Bennis, F., Sawanoi, A., \& Fugiwara, N. (2010). A framework for interactive work design based on motion tracking, simulation, and analysis. Human Factors and Ergonomics in Manufacturing \& Service Industries, 20(4), 339-352.

[6] The Economist (2012). Making the future: How robots and people team up to manufacture things in new ways. The Economist, April 21 ${ }^{\text {st }}, 2012$. Accessed 30/05/15: http://www.economist.com/node/21552897

[8] Almannai, B., Greenough, R., \& Kay, J. (2008). A decision support tool based on QFD and FMEA for the selection of manufacturing automation technologies. Robotics and Computer-Integrated Manufacturing, 24(4), 501-507.

[9] Maynard, H.B., Stegemerten, G.J., \& Schwab, J.L. (1948). Methods time measurement. New York: McGraw Hill.

[10] Chaffin, D. B., Anderson, G. B. J., \& Martin, B. J. (1999). Occupational Biomechanics (third ed.). Wiley-Interscience.

[11] Kühn, W. (2006, December). Digital factory: simulation enhancing the product and production engineering process. In Proceedings of the 38th conference on Winter simulation (pp. 1899-1906). Winter Simulation Conference. 
[12] Bertilsson, E., Högberg, D., \& Hanson, L. (2010). Digital human model module and work process for considering anthropometric diversity. Advances in Applied Digital Human Modeling, 568-575.

[13] Lowe, B. D., \& Krieg, E. F. (2009). Relationships between observational estimates and physical measurements of upper limb activity. Ergonomics, 52(5), 569-583.

[14] Dempsey, P. G., Mathiassen, S. E., Jackson, J. A., \& O'Brien, N. V. (2010). Influence of three principles of pacing on the temporal organisation of work during cyclic assembly and disassembly tasks. Ergonomics, 53(11), 1347-1358.

[15] Landsberger, H. A. (1958). Hawthorne Revisited: Management and the Worker, Its Critics, and Developments in Human Relations in Industry.

[16] Spielholz, P., Silverstein, B., Morgan, M., Checkoway, H., \& Kaufman, J. (2001). Comparison of self-report, video observation and direct measurement methods for upper extremity musculoskeletal disorder physical risk factors. Ergonomics, 44(6), 588-613. [17] Aristidou, A., \& Lasenby, J. (2013). Real-time marker prediction and CoR estimation in optical motion capture. The Visual Computer, 29(1), 7-26.

[18] Hignett, S., \& McAtamney, L. (2000). Rapid entire body assessment (REBA). Applied Ergonomics, 31(2), 201-205.

[19] Johnson, T.L., \& Fletcher, S.R. (2015). The limitations of using only CAD and DHM in design relating to high value manufacturing. In Sharples, S., Shorrock, S., and 
Waterson, P (Eds). Contemporary Ergonomics and Human Factors 2015: Proceedings of the International Conference on Ergonomics \& Human Factors 2015, Daventry, Northamptonshire, UK, 13-16 April 2015. Taylor \& Francis, pp. 329-332

[20] Fritzsche, L. (2010). Ergonomics risk assessment with digital human models in car assembly: Simulation versus real life. Human Factors and Ergonomics in Manufacturing \& Service Industries, 20(4), 287-299. 
2016-08-26

\title{
A study to trial the use of inertial non-optical motion capture for ergonomic analysis of manufacturing work
}

\author{
Fletcher, Sarah R.
}

Sage

Sarah R Fletcher, Teegan $L$ Johnson and John Thrower. A study to trial the use of inertial non-optical motion capture for ergonomic analysis of manufacturing work. Proceedings of the Institution of Mechanical Engineers, Part B: Journal of Engineering Manufacture, Volume 232, Issue 1, 2018, pp. 90-98

http://dx.doi.org/10.1177/0954405416660997

Downloaded from Cranfield Library Services E-Repository 